BIBLIOTIKA : Jurnal Kajian Perpustakaan dan Informasi

Volume 2 Nomor 1, 2018

Journal homepage : $\underline{\text { http://journal2.um.ac.id/index.php/bibliotika }}$

\title{
UPAYA PERPUSTAKAAN DALAM MELESTARIKAN KHAZANAH BUDAYA LOKAL (Studi Kasus Perpustakaan "HAMKA" SD Muhammadiyah Condongcatur)
}

\author{
Nurrohmah Hidayah* \\ Program Studi Interdisciplinary Islamic Studies Konsentrasi IImu Perpustakaan dan Informai Universitas Islam Negeri \\ Sunan Kalijaga Yogyakarta
}

A RTICLE INFO

Keyword:

Perpustakaan Sekolah,

Pelestarian Budaya,

Informasi

\begin{abstract}
A B S T R A C T
Tujuan dari penelitian ini adalah untuk mengetahui upaya yang dilakukan Perpustakaan " HAMKA" SD Muhammadiyah Condongcatur dalam melestarikan khazanah budaya lokal. Penelitian ini merupakan penelitian kualitatif dengan jenis penelitian deskriptif. Pendekatan yang digunakan adalah studi kasus. Informan dalam penelitian ini adalah pustakawan Perpustakaan "HAMKA" SD Muhammadiyah Condongcaturdipilih menggunakan teknik purposive sampling. Data diperoleh melalui wawancara, observasi, dan studi dokumentasi. Hasil penelitian menunjukkan bahwa upaya yang dilakukan Perpustakaan "HAMKA" SD Muhammadiyah Condongcatur dalam melestarikan budaya lokal yaitu dengan cara cultural knowledge, yaitu perpustakaan sebagai sarana memperoleh informasi tentang budaya lokal. Upaya tersebut melalui. (1) Pembuatan Rumah Literasi Budaya Agraris.(2) Display Wayang dan Batik untuk Media Pembelajaran, (3) Tangga Literasi Wayang dan Aksara Jawa. (4) Pembelajaran Perpustakaan Berbasis Budaya. dan (5) Penambahan Koleksi Budaya.
\end{abstract}

\section{PENDAHULUAN}

Perpustakaan menurut UU No 43 Tahun 2007 adalah institusi pengelola koleksi karya tulis, karya cetak, dan/atau karya rekam secara profesional dengan sistem yang baku guna memenuhi kebutuhan pendidikan, penelitian, pelestarian, informasi, dan rekreasi para pemustaka. Atas dasar itu, perpustakaan berarti memiliki beberapa fungsi. Namun sebagaimana umum dikenal, perpustakaan hanya dikenal sebagai tempat baca buku, penelitian, rekreasi dan sebagainya. Sebenarnya fungsi perpustakaan yang juga penting diperhatikan yaitu fungsi pelestarian.

Perpustakaan sebagai budaya khasanah bangsa. Keberadaan Perpustakaan tidak dapat dipisahkan dari budaya dan peradaban umat manusia. Tinggi rendahnya budaya dan peradaban suatu bangsa dapat dilihat dari kondisi perpustakaannya. Sehingga perpustakaan sebagai organisasi berkembang memiliki peran yang penting dalam melestarikan budaya bangsa (Lasa Hs, 2009). Melihat hal tersebut perpustakaan dewasa ini harus bisa menjadi fungsi pelestarian.

Selain itu fenomena sosial yang terlihat saat ini banyak masyarakat Indonesia tidak mengetahui budaya daerah Indonesia sendiri. Pengaruh budaya globalisasi telah menjadi sebuah ancaman bagi masyarakat Indonesia. Pengklaiman budaya Indonesia oleh Negara asing, lunturnya pengetahuan budaya asli Indonesia menjadi sebuah ancaman yang perlu dipikirkan bersama.. Olehkarena perpustakaan sebagai organisasi yang mempunyai fungsi pelestarian perlu berusaha membuat suatu program, layanan agar budaya Indonesia tetap terjaga.

Budaya merupakan warisan yang memiliki nilai tinggi bagi suatu bangsa. Budaya akan mengarahkan pemahaman anak bangsa terhadap suasana masyarakat dan perbedaannya, atmosfir politik yang

\footnotetext{
"Corresponding author.

E-mail addresses: Nurrohmahhidayah1@gmail.com (Nurrohmah Hidayah)
}

ISSN : 2579-3802 (Online) - BIBLIOTIKA : Jurnal Kajian Perpustakaan dan Informasi is licensed under Creative Commons AttributionShareAlike 4.0 International License (http://creativecommons.org/licenses/BY/4.0/).

21 | BIBLIOTIKA : Jurnal Kajian Perpustakaan dan Informasi 
mengitarinya, dan tingkat perkembangan intelektual yang melingkupinya. Warisan budaya dimaksud meliputi sesuatu yang berwujud seperti filosofi, nilai, keyakinan, kebiasaan, konvensi, adat istiadat, etika dan lain sebagainya. Sebagai negara yang kaya dengan khazanah budaya, sudah sepatutnya pemerintah dan seluruh elemen warga negara Indonesia untuk melestarikan warisan yang tinggi nilainya kemusnahan. Disinilah perlu peran perpustakaan untuk menyelamatkan warisan tersebut dengan mengumpulkan, menyimpan, mengawetkan, dan melestarikan hasil karya cipta, rasa dan karsa bangsa. Salah satu cara pelestarian informasi adalah melakukan transformasi melalui alih media dan promosi budaya (Nurjannah, 2017).

Perpustakaan mengembangkan fungsi pelestarian budaya(Bella, 2017) sesuai dengan kebutuhan pengunanya. Fungsi pelestarian perpustakaan sebagai sarana pelestarian tidak hanya menyediakan bahan bacaan tentang budaya konten local, namun dapat mengemas perpustakaan sebagai tempat yang bernuansa budaya lokal. Layanan-layanan budaya seperti, penyediaan gazebo budaya, corner budaya, pemutaran film berbasis budaya, maupun pembelajaran perpustakaan bernuansa budaya lokal.

Perpustakaan SD Muhammadiyah Codongcatur sebagai perpustakaan sekolah yang terletak di Depok Sleman, Yogyakarta. Perpustakaan sekolah yang mempunyai beberapa program perpustakaan yang bertujuan untuk memenuhi kebutuhan informasi seluruh warga sekolah dan mewujudkan fungsi perpustakaan, salah satunya sebagai fungsi pelastarian budaya. Hal ini seperti yang telah tercantum dalam UU No 43 Tahun 2007, bahwa perpustakaan berfungsi sebagai fungsi pelestarian.

Penelitian ini bertujuan untuk mengetahui sejauh mana Perpustakaan "HAMKA" SD Muhammadiyah Condongcatur melestarikan budaya lokal melalui layanan yang diberikan diperpustakaan. Pemilihan lokasi penelitian "HAMKA SD Muhammadiayah Condongcatur karena perpustakaan ini merupakan salah satu perpustakaan yang mampu menciptakan inovasi baru. Peneliti berusaha memperoleh informasi tentang hal yang mendasari hadirnya program layanan pelestarian budaya lokal melalui perpustakaan.

\section{METODOLOGI PENELITIAN}

Penelitian ini merupakan jenis penelitian kualitatif deskriptif dengan menggunakan metode studi kasus. Studi kasus merupakan kajian mendalam tentang peristiwa, lingkungan, dan situasi tertentu yang memungkinkan mengungkapkan atau memahami sesuatu (Sulityo-basuki, 2006: 113). Dalam penelitian ini, peneliti menggunakan sample yang bertujuan (purposive sampling), dimana narasumber/informan dipilih berdasarkan tujuan tertentu. Informan yang ditentukan merupakan orang-orang yang memahami benar dan terlibat secara langsung dalam upaya pelestarian budaya lokal melalui perpustakaan.

Peneliti memilih menggunakan metode wawancara dan observasi sebagai teknik pengumpulan data. Wawancara dilakukan kepada pustakawan sebagai informan dengan model wawancara campuran. Sedangkan dalam observasi dilakukan dengan terjun langsung melihat kegiatan apa saja yang dilakukan dalam upaya pelestarian budaya lokal melalui perpustakaan. Dengan metode penelitian tersebut, peneliti berharap dapat menjawab rumusan masalah peneliti yaitu, upaya perpustakaan dalam melestarikan khazanah budaya lokal.

\section{KAJIAN PUSTAKA \\ Perpustakaan Sekolah}

Perpustakaan Sekolah adalah perpustakaan yang tergabung pada sebuah sekolah, dikelola sepenuhnya oleh sekolah dan tujuan utama membantu sekolah untuk mencapai tujuan khusus dan tujuan pendidikan pada umumnya (Martoadmojo, Karmidi, 2009: 1-2). Tujuan perpustakaan sekolah yaitu( Sulistyo-Basuki, 2010: 2.16):

1. Membantu dan memperkuat tujuan pendidikan sebagaimana digariskan dalam misi dan kurikulum sekolah

2. Mengembangkan dan memperkuat kebiasaan dan kegemaran membaca dan belajar pada murid serta penggunaan perpustakaan sepanjang hayat.

3. Memberikan kesempatan untuk memperoleh pengalaman dalam menciptakan dan menggunakan informasi untuk pengetahuan, pemahaman, imajinasi, dan keceriaan.

4. Membantu murid dalam pembelajaran dan ketrampilan menilai serta menggunakan informasi .

5. Menyediakan akses informasi ke sumber informasi lokal, regional, nasional, dan global serta kesempatan yang mengekspos murid dan gagasan, pengalaman, dan opini yang beraneka ragam.

6. Mengorganisasi aktivitas yang mendorong kesadaran dan kepekaan kultural dan social.

7. Bekerja sama dengan murid, guru, pimpinan sekolah serta orang tua mencapai misi sekolah. 


\section{Pelestarian Budaya}

Kebudayaan adalan ialah seperangkat pengetahuan, kepercayaan, moral, hokum, kesenian, yang dijadikan pedoman bertindak dalam memecahlan persoalan yang dihadapi dalam memenuhi kebutuhan hidup. Subtansi kebudayaan ialah macam ide-ide dan gagasan manusia yang timbul di masyarakat. Subtansi kebudayaan itu sesndiri, berisi system pengethuan, nilai nilai, pandangan hidup, kepercayaan, persepsi, dan etos (jiwa kebudayaan) (Yusuf, Mundzirin, dkk, 2010: 5).

Pelestarian merupakan kegiatan atau yang dilakukan secara terus menerus, terarah dan terpadu guna mewujudkan tujuan tertentu yang mencerminkan adanya sesuatu yang tetap dan abadi, bersifat dinamis, luwes, dan selektif (Ranjabar 2006: 115). Mengenai pelestarian budaya lokal, pelestarian norma lama bangsa (budaya lokal) adalah mempertahankan nilainilai seni budaya, nilai tradisional dengan mengembangkan perwujudan yang bersifat dinamis, serta menyesuaikan dengan situasi dan kondisi yang selalu berubah dan berkembang (Ranjabar, 2006:114).

Salah satu tujuan diadakannya pelestarian budaya adalah untuk melakukan revitalisasi budaya (penguatan). Mengenai revitalisasi budaya Prof. A.Chaedar Alwasilah mengatakan adanya tiga langkah, yaitu: (1) pemahaman untuk menimbulkan kesadaran, (2) perencanaan secara kolektif, dan (3) pembangkitan kreatifitas kebudayaan. Pelestarian adalah sebuah upaya yang berdasar, dan dasar ini disebut juga faktor faktor yang mendukungnya baik itu dari dalam maupun dari luar dari hal yang dilestarikan. Maka dari itu, sebuah proses atau tindakan pelestarian mengenal strategi ataupun teknik yang didasarkan pada kebutuhan dan kondisinya masing-masing (Ranjabar, 2006:118).

Mengenai pelestarian budaya lokal, Ranjabar (2006:114) mengemukakan bahwa pelestarian norma lama bangsa (budaya lokal) adalah mempertahankan nilai-nilai seni budaya, nilai tradisional dengan mengembangkan perwujudan yang bersifat dinamis, serta menyesuaikan dengan situasi dan kondisi yang selalu berubah dan berkembang. Merujuk pada definisi pelestarian diatas, maka dapat didefinisikan bahwa yang dimaksud pelestarian budaya (ataupun budaya lokal) adalah upaya untuk mempertahankan agar/supaya budaya tetap sebagaimana adanya.

Bentuk-bentuk dalam pelestarian budaya (Aufar, 2012:56) :

1. Culture experience merupakan pelestarian budaya yang dilakukan dengan cara terjun langsung. Contohnya masyarakat dianjurkan mempelajari tarian daerah dengan baik, agar setiap tahunnya tarian ini dapat di tampilkan dan diperkenalkan pada khalayak dengan demikian selain melestarikan kita juga memperkenalkan kebudayaan kita pada orang banyak.

2. Culture knowledge merupakan pelestarian budaya dengan cara membuat pusat informasi kebudayaan. Sehingga mempermudah seseorang untuk mencari tahu tentang kebudayaan. Selain itu cara ini dapat menjadi sarana edukasi bagi para pelajar dan dapat pula menjadi sarana wisata bagi wisatawan yang ingin mencari tahu serta ingin berkunjunjung dengan mendapatkan informasi dari pusat informasi kebudayaan tersebut. Upaya pelestarian budaya sangat diharapkan untuk membangkitkan kembali pengetahuan masyarakat mengenai budaya yang ada di Indonesia agar tidak terkikis oleh budaya luar.

\section{PEMBAHASAN}

\section{Gambaran Umum Perpustakaan "HAMKA" SD Muhammadiyah Codongcatur}

Perpustakaan HAMKA SD Muhammadiyah Condongcatur merupakan perpustakaan sekolah yang berada di Jl. Ringroad Utara, Gorongan, Condongcatur. Perpustakaan HAMKA SD Muhammadiyah Condongcatur berdiri seiring dengan berdirinya SD Muhammadiyah Condongcatur, yakni pada tahun 1998. Perpustakaan HAMKA SD Muhammadiyah Condongcatur memiliki visi mewujudkan perpustakaan sekolah sebagai pendukung proses kegiatan belajar mengajar di SD Muhammadiyah Condongcatur. Sedangkan Misinya diantaranya yaitu, 1) Menjadikan perpustakaan sebagai tempat bagi warga sekolah (kepala sekolah, guru, murid, dan karyawan) untuk memperdalam informasi/ pengetahuan dari berbagai jenis bahan pustaka dengan membaca, mengamati, mencermati, dan mendengarkan, 2) Memberikan pelayanan prioma dengan senyum, salam, sapa, sopan dan santun, 3) Menumbuhkembangkan minat baca sebagai budaya warga sekolah, 4) meningkatkan kerjasama dengan perpustakaan dan pusat informasi lain, 5) Rekreasi intelektual bagi warga SD Muhammadiyah Condongcatur.

Perpustakaan HAMKA SD Muhammadiayah Condongcatur memiliki berbagai program kerja. Program kerja ini bertujuan untuk mewujudkan visi dan misi yang ingin dicapai. Program yang telah berjalan diantaranya pustakawan kecil, pangung boneka tangan, pojok leterasi, gazebo literasi, reading day.

\section{Upaya Perpustakaan Dalam Melestarikan Khazanah Budaya Lokal di Perpustakaan "HAMKA" SD Muhammadiyah Condongcatur}

Hasil penelitian ini terfokus pada kegiatan perpustakaan SD Muhammadiyah Condongcatur pada upaya kegiatan perpustakaan sebagai lembaga pelestarian budaya bangsa. Hal ini seperti yang tertuang 
dalam undang-undang nomor43 Tahun 2007 tentang Perpustakaan, bahwa sebagai salah satu upaya untuk memajukan kebudayaan nasional, perpustakaan merupakan wahana pelestarian kekayaan budaya bangsa .

Upaya Perpustakaan HAMKA SD Muhammadiyah Condongcatur dalam melestraikan budaya lokal dilakukan secara berkelanjutan melalui mulai tahun 2015. Ada beberapa bentuk kegiatan pelestarian budaya melalui perpustakaan melalui beberapa program. Berikut upaya Perpustakaan HAMKA SD Muhammadiyah Condongcatur dalam upaya pelestarian budaya lokal:

1. Pembuatan Rumah Literasi Budaya Agraris

Rumah Literasi Budaya Agraris ini merupakan layanan yang diberikan Perpustakaan "HAMKA" SD Muhammadiyah Condongcatur dalam mengenalkan budaya pertanian zaman dahulu. Konsep layanan ini dibuat mengunakan bekas kandang kerbau, yang diletakan didepan pintu masuk sekolah. Layanan ini berisikan alat-alat pertanian tradisional jawa, seperti luku, garu, lumpang dan alat rumah tangga seperti gentong, lesung, dll. Selain menampilkan beberapa alat pertanian layanan ini juga memuat buku-buku mengenai budaya-budaya zaman dahulu mengenai pertanian. Pembuatan Rumah Budaya Leterasi Agraris ini, bertujuan untuk mengenalkan siswa tentang budaya pertanian masa lampau kepada siswa. Upaya ini dilakukan karena perpustakaan menyadari bahwa sekarang ini siswa tidak mengetahui budaya pertanian zaman dahulu.

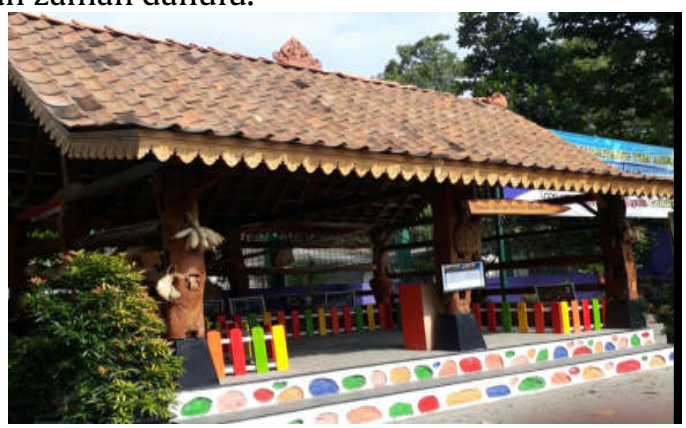

Rumah Leterasi Budaya Agraris (Dokumen Pribadi)

2. Display Wayang dan Batik untuk Media Pembelajaran

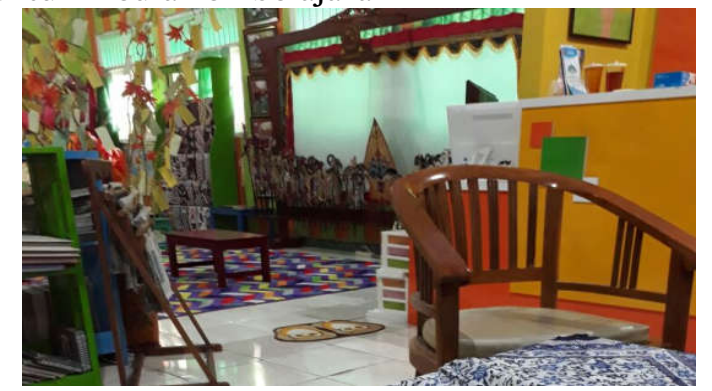

Display Wayang dan Batik (Dokumen Pribadi)

Display Wayang ini ditampilkan di ruang Perpustakaan. Wayang di display menggunakan kelir lengkap dengan lampu. Beberapa tokoh wayang seperti pandawa dan kurawa juga didisplay. Pustakawan juga membuat buku diskripsi tentang tokoh-tokoh wayang, seperti karakter dan sifat masing masih tokoh wayang. Selain itu perpustakaan "HAMKA" mempunyai display batik kas Yogyakarta yang termasuk budaya lokal.. Layanan ini bertujuan untuk mengenalkan kepada siswa budaya wayang jawa dan batik, beserta karakternya yang dapat dicontoh maupun tidak oleh siswa.

3. Tangga Literasi Wayang dan Aksara Jawa

Tangga literasi wayang aksara ini diletakan di tangga sekolah. Di dekat pojok baca perpustakaan. Hal ini bertujuan mengenalkan siswa aksara jawa dan tokoh wayang. Hal ini memudahkan siswa dalam mengingat budaya lebih dekat.

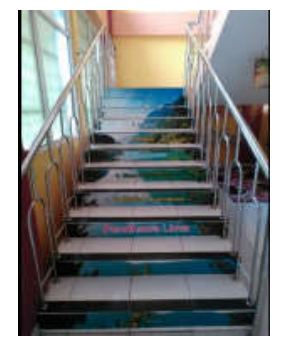

Tangga Literasi Budaya Lokal 
4. Pembelajaran Perpustakaan Berbasis Budaya

Pembelajaran perpustakaan berbasis budaya ini dilakukan dengan di perpustakaan. Perpustakaan bekerjasama dengan guru mata pelajaran dalam mengenalkan budaya melalui perpustakaan. Perpustakaan "HAMKA" SD Muhammadiyah Condongcatur sebagai sarana tempat memperoleh informasi mengenai budaya, baik koleksi maupun alat peraga.

5. Koleksi Budaya

Perpustakaan "HAMKA" SD Muhammadiyah Condongcatur juga mempunyai koleksi mengenai budaya, seperti permainan tradisional, wayang, pepak basa jawa, dll. Hal ini bertujuan dalam menunjang kegiatan belajar mengajar siswa. Selain itu juga sebagai pendukung layanan budaya. Koleksi ini diletakakan didekat layanan budaya yang diberikan. Sehingga pemustaka dapat mudah memperoleh informasi.

Berdasarkan hasil observasi dan wawancara, secara garis besar, upaya perpustakaan "HAMKA" dalam melestraikan budaya masih dalam bentuk culturure knowledge, yaitu merupakan pelestarian budaya dengan cara membuatpusat informasi kebudayaan melalui perpustakaan, sehingga siswa dapat mencari tahu tentang kebudayaan melalui literature literature yang ada di perpustakaan. Selain itu perpustakaan dapat dijadikan sarana edukasi bagi siswa SD Muhammadiyah Condongcatur yang ingin tahu budaya lokal jawa, seperti wayang, aksara jawa, batik, alat pertanian tradisional dan lain sebagainya.

Dari hasil wawancara dengan kepala perpustakaan SD Muhammadiyah Condongcatur Perpustakaan HAMKA SD Muhammadiyah Condongcatur (20 Maret 2018) mengungkapkan bahwa perpustakaan HAMKA SD Muhammadiyah Condongcatur kedepannya akan berusaha mewujudkan perpustakaan berbasis makers space dalam program renstra tahun 2019, yaitu tempat perpustakaan memberikan sarana bagi siswa untuk bereksperimen membuat suatu produk. Hal ini akan dikolaborasikan dengan konsep budaya. Seperti cara pembuatan batik, miniature wayang dll. Melihat hal tersebut perpustakaan "HAMKA" SD Muhammadiyah Condongcatur berusaha ingin mewujudkan bentuk pelestraian budaya dengan cara . Culture experience, yaitu dimana perpustakaan ingin mengajarkan kepada siswa pengalaman langsung mengenai budaya itu sendiri.

\section{Kendala-Kendala yang di Hadapi dalam Upaya Pelestarian}

Upaya perpustakaan dalam melestarikan budaya lokal di Perpustakaan "HAMKA" SD Muhammadiyah Condongcatur berdasarkan penelitian ini memiliki beberapa kendala yang menurut peniliti harus diperbaiki untuk mengoptimalkan upaya tersebut tersebut. Kendala-kendala tersebut adalah:

1. Kebijakan

Setiap organisasi atau lembaga pasti memiliki kebijakan untuk mengatur seluruh kegiatan yang ada di organisasi tersebut. Kebijakan tersebut dibuat untuk memberikan batasan dan acuan dari kegiatan yang harus dilaksanakan agar sesuai dengan tujuan. Tidak adanya kebijakan baku mengenai proses kegiatan mengenai cara literasi budaya yang jelas. Sehingga perlu dibuat sebuah SOP pengunaan layanan pelestrian budaya tersebut, dapat berupa integrasi kurikulum yang jelas.

2. Sumber Daya Manusia

Salah satu bagian yang penting dalam menjalankan suatu kegiatan adalah sumber daya manusia. Karena merekalah yang bertanggung jawab dalam kegiatan tersebut. Dari segi kuantitas SDM pustakawan ini masih kurang dalam mengoptimalkan layanan pelestrian budaya.

\section{KESIMPULAN}

Upaya yang dilakukan Perpustakaan "HAMKA" SD Muhammadiyah Condongcatur dalam mengurangi melestarikan budaya lokal yaitu dengan cara cultural knowledge, yaitu perpustakaan sebagai sarana pemperoleh informasi tentang budaya melalui perpustakaan. Upaya tersebut yaitu (1)nPembuatan Rumah Literasi Budaya Agraris. (2) Display Wayang dan Batik untuk Media Pembelajaran.(3) Tangga Literasi Wayang dan Aksara Jawa. (4) Pembelajaran Perpustakaan Berbasis Budaya, dan (5) Penambahan Koleksi Budaya.

\section{DAFTAR RUJUKAN}

Aufar, I. (2012). Pengertian Kebudayaan. Makalah tidak diterbitkan. Fakultas Teknik Industri Universitas Gunadharma,Jakarta.

Bella, K. O. (2017). Peranan Perpustakaan Dan Museum Tembakau Dalam Pelestarian Kebudayaan Kota JEMBER. BIBLIOTIKA: Jurnal Kajian Perpustakaan Dan Informasi, 1(1), 42-57. https://doi.org/10.17977/um008v1i12017p042 
Karmidi Martoadmojo. (2009). Pelayanan Bahan Pustaka. Jakarta: Universitas Terbuka.

Lasa, Hs. (2009). Peran Perpustakaan dalam Melestarikan Budaya dan Membangun Peradaban. Dalam repository.umy.ac.id. Diakses pada 29 Maret 2018 pukul 08.30 WIB.

Nurjannah. (2017). Eksistensi Perpustakaan dalam Melestarikan Khazanah Budaya Bangsa. LIBRIA, Vol. 9, No. 2, Desember 2017

Ranjabar, Jacobus.( 2006). Sistem Sosial Budaya Indonesia. Bogor :Ghalia Indonesia Sulistyo Basuki. (2010). Pengantar Ilmu Perpustakaan. Jakarta: Universitas Terbuka Sulistyo-Basuki. (2006). Metode Penelitian. Jakarta: Wedatama Widya Sastra.

Yusuf, Mundzirin, dkk. (2005). Islam Budaya Lokal. Yogyakarta: Pokja Akademik UIN Sunan Kalijaga 